\title{
Wireless Bioelectronic Nanosystems for Intracellular Communication
}

Paola Sanjuán-Alberte, Sidahmed A Abayzeed, Rafael Fuentes-Domínguez, María E Alea-Reyesd, Matthew Clark, Richard Hague, Morgan Alexander, Lluïsa Pérez-García, Frankie Rawson

Submitted date: 21/09/2018 Posted date: 21/09/2018

Licence: CC BY-NC-ND 4.0

Citation information: Sanjuán-Alberte, Paola; Abayzeed, Sidahmed A; Fuentes-Domínguez, Rafael;

Alea-Reyesd, María E; Clark, Matthew; Hague, Richard; et al. (2018): Wireless Bioelectronic Nanosystems for Intracellular Communication. ChemRxiv. Preprint.

In order for the field of bioelectronics to make an impact on healthcare, there is an urgent requirement for the development of "wireless" electronic systems to both sense and actuate cell behaviour. Herein we report the first example of an innovative intracellular wireless electronic communication system. We demonstrate that chemistry can be electrically modulated in a "wireless" manner on the nanoscale at the surface of conductive nanoparticles uptaken by cells at unreported low potentials. The system is made functional by modifying gold nanoparticles incorporating a Zn-porphyrin, which are taken up by cells and are shown to be biocompatible. It is demonstrated the redox state of Zn-porphyrin modified gold nanoparticles is modulated and reported on fluorescently when applying an external electrical potential. This provides an attractive new "wireless" approach to develop novel bioelectronic devices for modulating and sensing cellular behaviour using intracellular monitoring.

File list (2)

Wireless bioelectronic nanosystem for intracellular commu... (1.72 MiB) view on ChemRxiv • download file Vid.xspf (557.00 B) view on ChemRxiv - download file 


\section{Wireless bioelectronic nanosystems for intracellular}

\section{communication}

Paola Sanjuán-Alberte ${ }^{a, b}$, Sidahmed A Abayzeed ${ }^{c}$, Rafael Fuentes-Domínguez ${ }^{c}$, María E Alea-

Reyes $^{d}$, Matthew Clark ${ }^{c}$,Richard JM Hague ${ }^{b}$, Morgan R Alexander ${ }^{e}$, Lluïsa Pérez-Garcia ${ }^{e}$, Frankie J Rawson ${ }^{a *}$

${ }^{a}$ Regenerative Medicine and Cellular Therapies, School of Pharmacy, University of Nottingham, Nottingham, NG7 2RD UK

${ }^{\mathrm{b}}$ Centre for Additive Manufacturing, Faculty of Engineering, University of Nottingham, Nottingham, NG7 2RD, UK

${ }^{c}$ Optics and Photonics Research Group, Faculty of Engineering, University of Nottingham, Nottingham, NG7 2RD, UK

${ }^{\mathrm{d}}$ Departament de Farmacologia, Toxicologia i Química Terapèutica, Universitat de Barcelona, Avda. Joan XXIII 27-31, 08028 Barcelona, Spain

${ }^{\mathrm{e}}$ Advanced Materials and Healthcare Technologies, School of Pharmacy, University of Nottingham, Nottingham, NG7 2RD, UK 
Keywords: Wireless Bioelectronics, Bioelectronic Medicine, Nanotechnology, Intracellular Communication

\section{Abstract}

In order for the field of bioelectronics to make an impact on healthcare, there is an urgent requirement for the development of "wireless" electronic systems to both sense and actuate cell behaviour. Herein we report the first example of an innovative intracellular wireless electronic communication system. We demonstrate that chemistry can be electrically modulated in a "wireless"

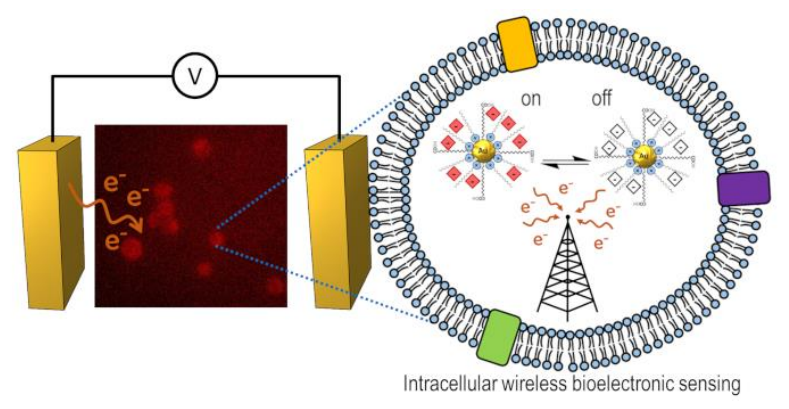
manner on the nanoscale at the surface of conductive nanoparticles uptaken by cells at unreported low potentials. The system is made functional by modifying gold nanoparticles incorporating a Zn-porphyrin, which are taken up by cells and are shown to be biocompatible. It is demonstrated the redox state of Zn-porphyrin modified gold nanoparticles is modulated and reported on fluorescently when applying an external electrical potential. This provides an attractive new "wireless" approach to develop novel bioelectronic devices for modulating and sensing cellular behaviour using intracellular monitoring.

The field of bioelectronic medicine offers a new paradigm in therapeutic intervention ${ }^{1,2}$. The technology is in its infancy, but relies on the ability to merge electronic devices with biology to then be used to sense and actuate cell/tissue and organ behaviour ${ }^{3}$. The key challenge in advancing the field further is to develop new non-invasive methods to both electrically sense and actuate cell 
behaviour. Our group ${ }^{4-6}$ and others ${ }^{7-10}$ have pioneered new methods for electrically communicating with the internal environment of a cell via use of nanowire electrodes. However, these methods tend to be invasive in nature as they necessarily have to pierce the plasma membrane which can lead to cell perturbations ${ }^{11,12}$. In addition, these electrodes require physical electrical connectivity from inside of the cells to the outside, thus hindering their use in more complex biological environments. Therefore, an approach to addressing these issues is to develop novel wireless electronic systems for the development of intracellular sensors and actuators. The development of novel bioelectronics using such a wireless-electronic approach may subsequently enable significant advancements in the ability to use intracellular electronics to facilitate cell communication and actuation. Therefore, the aim of this work was to develop a new bioelectronic approach for sensing electrical changes in response to the application of an externally applied voltage inside biological cells, thereby offering the first example of a wireless electronic tool to modulate redox inside of cells ${ }^{13-14}$.

The work undertaken was inspired by the fields of bipolar electrochemistry and drug delivery. Bipolar electrochemistry (also known as wireless electrochemistry) relies on placing a conductive particle between feeder electrodes which have potential difference placed across them. This causes the conductive particle to polarise and in doing so, causes a potential difference between the electrolyte and poles of the particle, consequently providing the thermodyamic driving force required to modulate redox reactions ${ }^{13-15}$. In that approach however the magnitude of the voltages required at the nanoscale is in the $\mathrm{kV}$ range ${ }^{16}$ which was thought to preclude its use in biology. Nanoparticles have been used as drug delivery vectors for a number of years. In particular one mechanism that has been used to deliver payloads to cells are conductive gold nanoparticles ${ }^{17}$. 
These have been shown to be uptaken by cells in a non-invasive manner, are biocompatible ${ }^{18,19}$ and have been extensively reviewed ${ }^{20-22}$. Their use in drug delivery research is widespread because the surface of gold is readily adaptable to surface chemistry modifications, facilitating functionalisation of the nanoparticle with drugs. We hypothesised that by using conductive gold nanoparticles, which could be functionalised with a redox reporter, we could then polarise these nano-particles, through application of an external electric field, to report on voltage induced changes by wireless modulation of the redox moiety attached to the gold nanoparticles. Thereby demonstrating a new wireless bioelectronic communication nanosystem.

Our strategy for developing a wireless bioelectronic tool included three key steps: (1) Firstly, we establish evidence that biocompatible lower potentials were capable of causing wireless electrical induced redox effects at gold nanoparticles. This was achieved by modulating the electrochemical deposition of palladium in a wireless manner. (2) Development of a Dark Field Microscopy tool was undertaken in order to provide direct evidence that gold nanoparticles could be used as electronic sensors at low voltages. This was achieved by imaging the electrical surface charge via plasmonic effects on the gold nanoparticles. (3) We then took gold nanoparticles modified with a Zn(II)meso-tetrakis(4-carboxylateyphenyl)porphyrin sodium salt (Na-ZnTCPP), which were fluorescent. These particles were incubated with Chinese Hamster Overy (CHO) cells and were taken up inside. We showed that the modified gold nanoparticles could act as electrical reporters, when applying an external electric field, by modulating the redox state of the NaZnTCPP, which could be optically followed by fluorescence microscopy.

The goal of this work was to develop a new wireless nano-electronic communication system inside of cells. The work was in part motivated by bipolar electrochemistry for which most reported cases have been achieved at the macro/micro-scale ${ }^{13,14}$. Therefore to extend this approach to the 
dimensions required for intracellular measurement, we initially set out to investigate the effect of placing $50 \mathrm{~nm}$ sized unmodified gold nanoparticles (u-AuNPs) between electrodes after application of a potential difference. The u-AuNPs were commercially purchased and were stabilised with citrate. They were placed in an aqueous solution in the presence and absence of 1 $\mathrm{mM}$ palladium chloride $\left(\mathrm{PdCl}_{2}\right)$ and a potential difference was applied between the feeder electrodes. Potentials were applied using an inkjet printed electrochemical cell consisting on two gold feeder electrodes with a separation of $210 \mu \mathrm{m}$ and a silver/silver chloride pseudo-reference electrode (Figure S1), which was characterised using cyclic voltammetry prior to use (Figure S2).

We envisaged that the u-AuNPs would align in the electric field polarising thereby causing a potential difference between the poles. This potential difference could then provide sufficient energy to reduce $\mathrm{Pd}^{+2}$ (aq) thereby depositing $\mathrm{Pd}^{0}(\mathrm{~s})$ on the surface of the u-AuNPs as depicted in Figure 1A. After applying the electrical input of $10 \mathrm{~V}$ at the varying times of $0,1,5$ and 15 minutes, we collected the solutions of $\mathrm{u}$-AuNPs containing $\mathrm{PdCl}_{2}$ and characterised the size of the particles by Dynamic Light Scattering (DLS). The u-AuNPs in the suolution that were not exposed to the potential difference of $10 \mathrm{~V}$ were estimated to have a size of $50 \mathrm{~nm}$. In the presence of the palladium chloride the size increased to $108.3 \pm 1.3 \mathrm{~nm}$. After one minute of applying $10 \mathrm{~V}$ there was no difference in the size of the nanoparticles when compared to those which were not exposed to a potential difference of $10 \mathrm{~V}$ (Figure 1B). After exposure to the potential difference for 5 and 15 minutes there was a significant difference in size of the u-AuNPs in the presence and absence of the $\mathrm{PdCl}_{2}$ with an increase in size to approximately $745.5 \pm 51.8 \mathrm{~nm}$ and $718.0 \pm 38.4 \mathrm{~nm}$, respectively. This was also reflected in the colour of the collected solution, becoming red to blue and then coloured (Figure 1B inset), which is a well-known phenomenon that, depending on the size of the gold nanoparticle, the SPR peak in absorption spectrum shifts resulting in different 
coloured solutions depending on the size of the gold particles. We suggest that this difference in size occurs because the reduction of the palladium and oxidation of the chloride ions occurs at the surface of u-AuNPs (Figure 1A), leading to deposition of $\operatorname{Pd}_{(s)}^{0}$ nanoparticles (Figure 1A) and resulting in larger particles. We investigated the size or particles further and provide additional evidence of the mechanism resulting in the increase in size. Consequently, we placed the different samples into a holey carbon grid and performed scanning electron microscopy (SEM) investigations, coupled with Energy Dispersive X-ray (EDX) on the $\mathrm{Pd}^{0}{ }_{(\mathrm{s})} \mathrm{u}$-AuNPs. Large micron sized clumps (Figure 1C) were observed, and elemental mapping with EDX indicated that there was a distribution of $\mathrm{Pd}$ and $\mathrm{Au}$ suggesting the application of an electric field resulted in the wireless electrodeposition of $\mathrm{Pd}^{0}(\mathrm{~s})$ on the gold. This significant finding demonstrates the feasibility to "wirelessly" mediate redox reactions at the surface of the gold nanoparticles, without the need for any physical wiring to the gold nanoparticles. The discrepancy between the sizes of particle observed when analysing with DLS and those analysed with SEM (700 nm measured by DLS vs $10 \mu \mathrm{m}$ agglomerates observed by SEM) may be due to differences in preparation of samples. In the DLS experiments the nanoparticles were in solution and in the TEM they were dried. The important thing to note though, was that the increase in size of the gold nanoparticles only occurred when applying an electric field and a potential difference between the feeder electrodes, indicating that applying the potential difference between the feeder electrodes induces the wireless modulation of redox effects at the gold nanoparticle solution interface. This redox mediated deposition at gold nanoparticles displayed some unique properties since the deposition was occurring at relatively low potentials compared to the other electrical induced redox effect investigated at the nanoscale, which required application of $\mathrm{kV}^{16}$. However, we tentatively suggest 
it could be due to plasmon effects which lower the energetics associated with electronically modulating the redox reactions ${ }^{23,24}$.

A
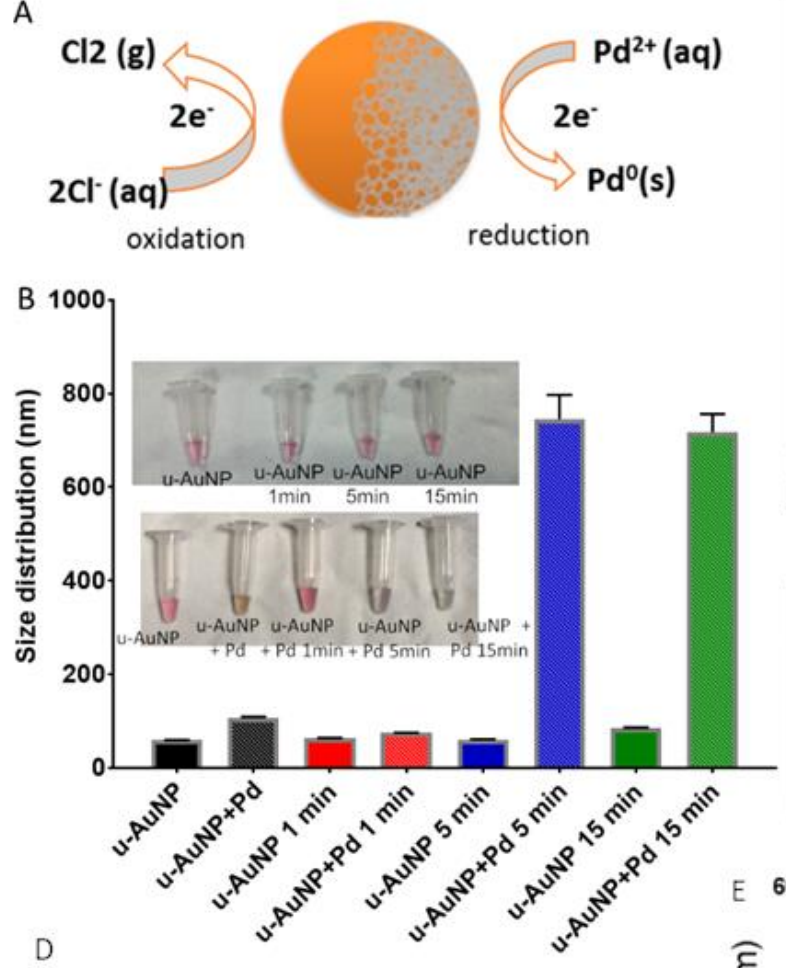

D

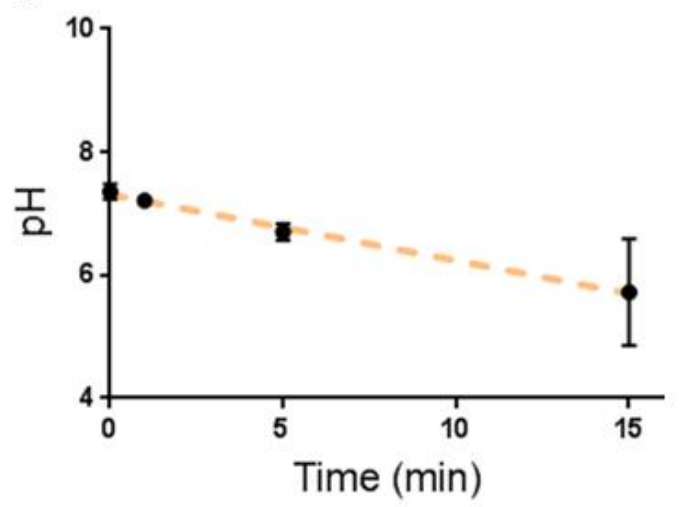

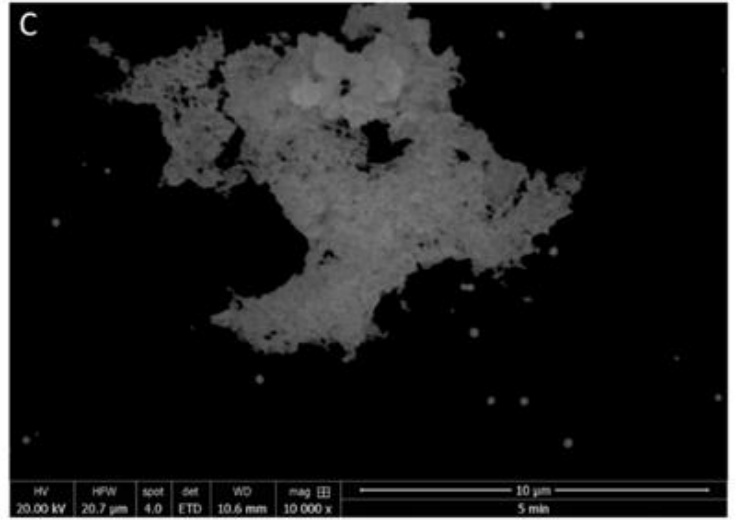
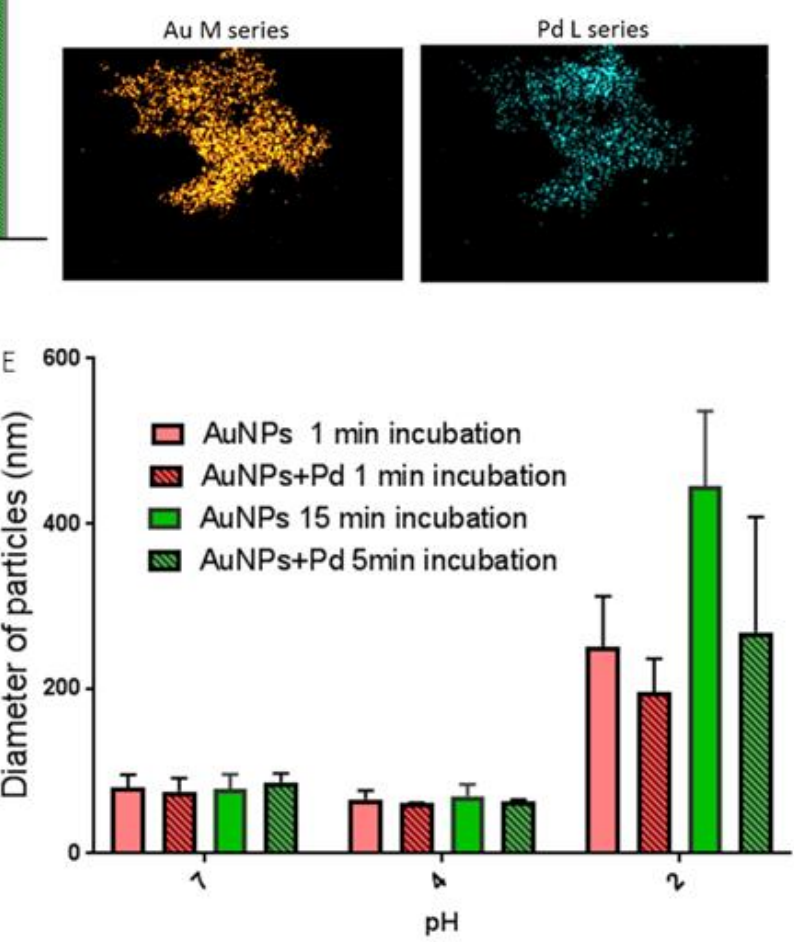

Figure 1. (A) Diagrammatic representation of proposed electrical induced reaction in unmodified gold nanoparticles (u-AuNPs). $10 \mathrm{~V}$ vs $\mathrm{Ag} / \mathrm{AgCl}_{2}$ was applied to solutions of u-AuNPs and uAuNPs in the presence of $\mathrm{PdCl}_{2}$ for 1,5 and 15 min and the size of $\mathrm{u}-\mathrm{AuNPs}$ was (B) measured 
by DLS ( $\mathrm{n}=3$ : $\mathrm{S}$ and (C) analysed by SEM (top) coupled with Energy Dispersive X-ray technology, where the Au M series can be seen in orange and Pd L series in blue (bottom). (D) Effect of applying $10 \mathrm{~V}$ between 0 and 15 minutes on the $\mathrm{pH}$ of the solution. (E) Dynamic light scatter study of AuNP in the presence and absence of $1 \mathrm{mM} \mathrm{PdCl}_{2}$ on buffer solutions at $\mathrm{pH} 7,4,2$. ( $\mathrm{n}=3$; SD)

At the magnitude of the potential applied, water electrolysis would occur at the feeder electrodes and therefore protons would be generated; we therefore sought to establish the effect of the production of proton on Pd deposition on the Au to ensure the electronic effect was not an indirect one mediated by electrolysis of water. Accordingly, we measured the $\mathrm{pH}$ of the solution containing u-AuNPs and $\mathrm{PdCl}_{2}$ at $0,1,5$ and 15 minutes after applying a potential difference of $10 \mathrm{~V}$ between the feeder electrodes. It was demonstrated that there was a linear correlation between the $\mathrm{pH}$ of the solution and the time that potentials were applied $\left(\mathrm{R}^{2}=0.995\right)$, i.e. with a change in $\mathrm{pH}$ from $7.36 \pm 0.13$ to $5.72 \pm 0.87$ after 15 minutes of application of $10 \mathrm{~V}$ (Figure 1D). To rule out the possibility that aggregation was being mediated by changes in the $\mathrm{pH}$ via this proton generation, to investigate this further, u-AuNPs were incubated in the presence and absence of 1 $\mathrm{mM} \mathrm{PdCl}_{2}$ in buffer solutions at $\mathrm{pH} \mathrm{2,4}$ and 7 for 1 and 15 minutes (Figure 1E). The size of the nanoparticle was analysed by DLS showing that at $\mathrm{pH} 7$ and 4 there was no change in size for any of the solutions. However, at $\mathrm{pH} 2$ there was a significant increase in the size of nanoparticles confirming such acidic $\mathrm{pH}$ could induce aggregation of the nanoparticles due to instabilities on the surfaceproduced by protonation of the citrate molecule ${ }^{25}$. Nevertheless, as the $\mathrm{pH}$ recorded with an application of potential for 15 minutes only resulted in a reduction of the $\mathrm{pH}$ to 5.72 , the premise that protons play any significant part in particle aggregation upon $\mathrm{Pd}^{2+}$ reduction and the increases 
in size of the nanoparticles can be rejected. Therefore, this provides further evidence that the change in size of the nanoparticle on application of an electrical input occurs due to u-AuNPs being directly affected by the electrical input, resulting in wireless redox induced communication with the nanoparticles via $\mathrm{Pd}^{2+}$ reduction.

Our observations suggested that we could wirelessly drive redox chemistry via the application of an electrical field at a low potential difference that was orders of magnitude lower to that reported at other nanostructures, such as carbon nanotubes $(\mathrm{CNTs})^{16}$. To further prove our hypothesis that redox reactions could be triggered at relatively low voltage, we explored an alternative label-free approach based on the voltage sensitivity of plasmonic nanostructures ${ }^{26-31}$. To test the effect of low voltage on u-AuNP, we used a darkfield microscopy approach to monitor the dynamics of the voltage-modulated intensity of light scattered by the nanoparticles. $125 \mathrm{~nm}$ gold nanoparticles were immobilised on a glass slide coated with Indium-Tin-Oxide (ITO) to be used as a working electrode in a two-electrode electrochemical cell. A darkfield microscopy image of these gold nanoparticles is presented in Figure 2A. On application of the electrical potential there is a shift in the plasmon resonance which is proportional to the charge density. To detect the charge density modulation with high spatial resolution, we then applied a relatively low alternating voltage $(0.8 \mathrm{Vpp}, 4 \mathrm{~Hz})$. The voltage effect was mapped by computing a fast Fourier transform (FFT) of the time-varying intensity at each pixel. By selecting the amplitude of the intensity modulation at the frequency of the applied signal (i.e. $4 \mathrm{~Hz}$ ), a map of the charge density effect is produced as shown in Figure 2B. It is worth commenting that these signals are acquired at a scale of $200 \mathrm{~nm}$ (i.e. the pixel size). A signal at the single nanoparticle scale (Figure 2C) is shown in Figure 2D which confirmed that we could observe intensity modulation at $4 \mathrm{~Hz}$ that corresponds to the frequency of the applied voltage signal. Therefore, it is experimentally confirmed that 
voltage modulated resonance position is proportional to charge density ${ }^{28}$ and this can be used for quantitative imaging of the electric field in a subsequent work.

These results bring out the conclusion that observing localised resonance position modulation on applying a potential difference confirms the accumulation of electrical change around the gold nanoparticle at low potentials. Thus this supports our early assertion that $\mathrm{u}$-AuNPs are acting as electrical actuators at relatively low voltages.

A

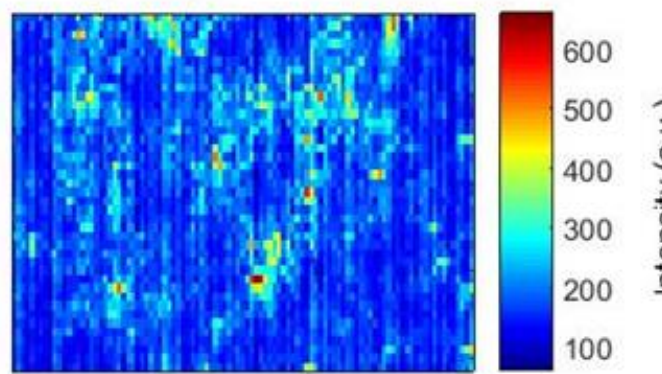

$\mathrm{C}$

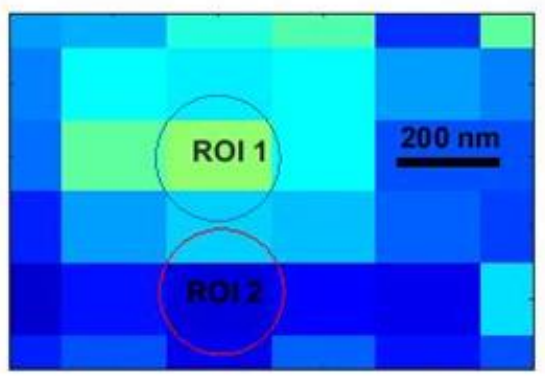

B
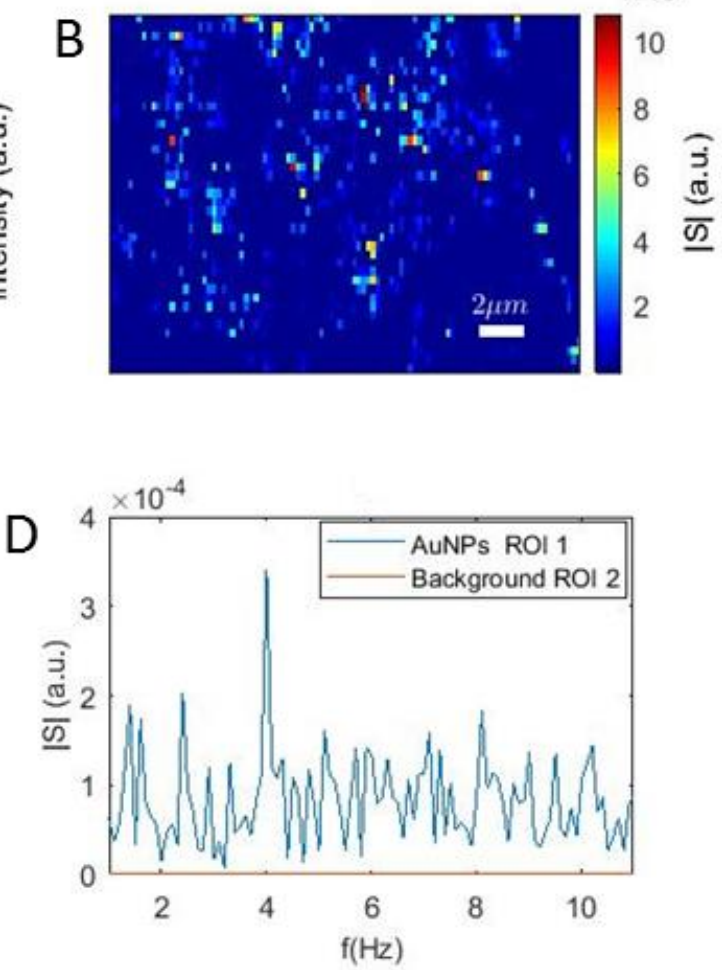

Figure 2. Microscopy images of voltage sensing by plasmonic nanoparticles. (A) A darkfield microscopy images of Au nanoparticles; (B) a map of the amplitude of the voltage-modulated scattering intensity $(|\mathrm{S}|)$ of $125 \mathrm{~nm}$ Au nanoparticles, presented to support that low-voltage can be detected by Au nanoparticles and therefore can be used as electronic sensors. (C) A magnified view of the darkfield image where the intensity modulation spectrum (D) is obtained. 
To develop the wireless electrical approach further in order to facilitate an intracellular communication system, our strategy was to combine a recently developed surface modification procedure. This used a gemini pyridinium based amphipile which mediated the incorporation of Na-ZnTCPP onto water-soluble gold nanoparticles (ws-AuNPs) ${ }^{32}$ (Figure 3A) with the electrical input. We predicted that the Na-ZnTCPP would act as a redox reporter by analysing the changes in its fluorescence. The premise for this was built on the fact that we know that the oxidation state of the Na-ZnTCPP effects the fluorescent intensity ${ }^{33}$. We envisaged that by converting the electrical input into an optical output we could electronically communicate with the internal environment of a cell. Others have noted that, on application of voltages at Zn-porphyrin modified electrodes, the redox state of the porphyrin could be modulated ${ }^{34}$; however, this had never been previously achieved in a wireless manner in a cell as reported in later text. To do this, we initially characterised the size of the ws-AuNPs prior and after the incorporation of the Na-ZnTCPP (Figure 3B) performed with DLS. The mean size of the particle was approximately $40 \mathrm{~nm}$ before and 60 $\mathrm{nm}$ after adding the Na-ZnTCPP. This was an indication that the Na-ZnTCPP had been incorporated, thereby increasing particle size. This resulted from the electrostatic interactions between the positive charge of the bis-pyridinium salt conforming the shell of the ws-AuNPs and the negative charge of the Na-ZnTCPP after the modification. We also characterised them by TEM (Figure 3C) which resulted in a mean size of $70 \mathrm{~nm}$. Interestingly, a halo can be seen in the TEM images which represent the surface modification of the Na-ZnTCPP modified ws-AuNPs.

The steady state absorbance and emission spectra obtained for solutions of free Na-ZnTCPP, ws-AuNPs and Na-ZnTCPP modified ws-AuNPs are shown in Figure 3D. Absorbance spectrum of a solution of 1,17 mM Na-ZnTCPP in PBS showed an intense and defined Soret band at 422 
$\mathrm{nm}$ and two $\mathrm{Q}$ bands characteristic of zinc porphyrins $\mathrm{s}^{32,35}$. A less intense Soret band is also present in the Na-ZnTCPP modified ws-AuNPs. Solutions containing Na-ZnTCPP modified ws-AuNPs present smaller concentrations of porphyrin than those of free ZnTCPP, corresponding to $1.26 \mu \mathrm{M}$ $\mathrm{Na}-\mathrm{ZnTCPP}$ and thus there is a reduction in the intensity of the peak at $422 \mathrm{~nm}$. Regarding the emission spectrum, no observable fluorescent signal was obtained for ws-AuNPs over the wavelength range applied between 550 and $750 \mathrm{~nm}$ at $\lambda_{\text {exc }}$ of $420 \mathrm{~nm}$. Whereas peaks in the free Na-ZnTCPP spectrum at approximately $625 \mathrm{~nm}$ and $655 \mathrm{~nm}$ were observed, respectively. These peaks result from the fluorescence associated with the porphyrin ${ }^{32,36}$, which can also be seen in the emission spectrum of Na-ZnTCPP modified ws-AuNPs as we viewed peaks at the equivalent position. No observable fluorescence was noted at the ws-AuNPs, but after performing the surface modification procedure we observed peaks at the same position as the free Na-ZnTCPP, suggesting the particles were modified with the Na-ZnTCPP as depicted in Figure 3A. Moreover, it was noted that the emission peak ratios was inverted when compared to the free molecule, which may be attributed to the differing configurations of the electrons when the molecule is bound to the surface $^{35}$. These data combined confirm that we have successfully modified the particles as indicated. 
A
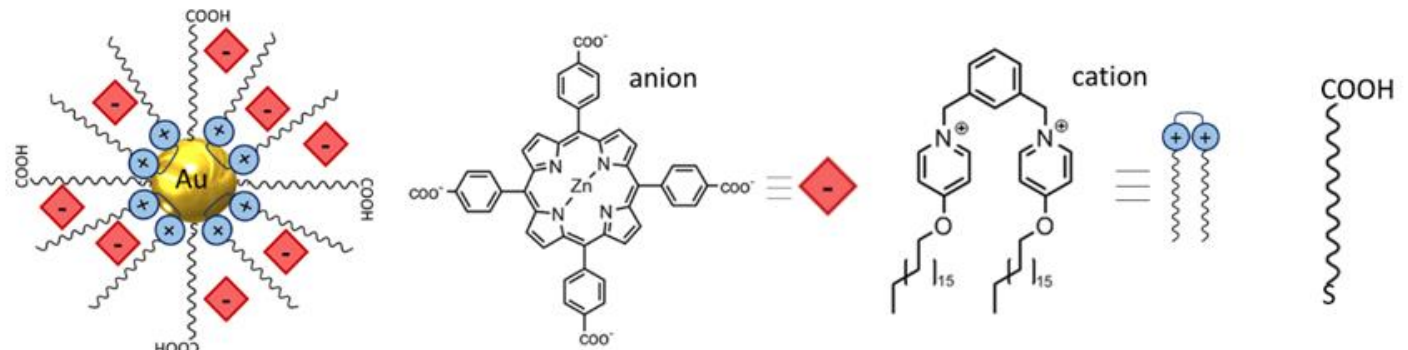

ZnTCPP modified water soluble gold nanoparticle (ws-AuNP)

Zn-Porphyrin (ZnTCPP)
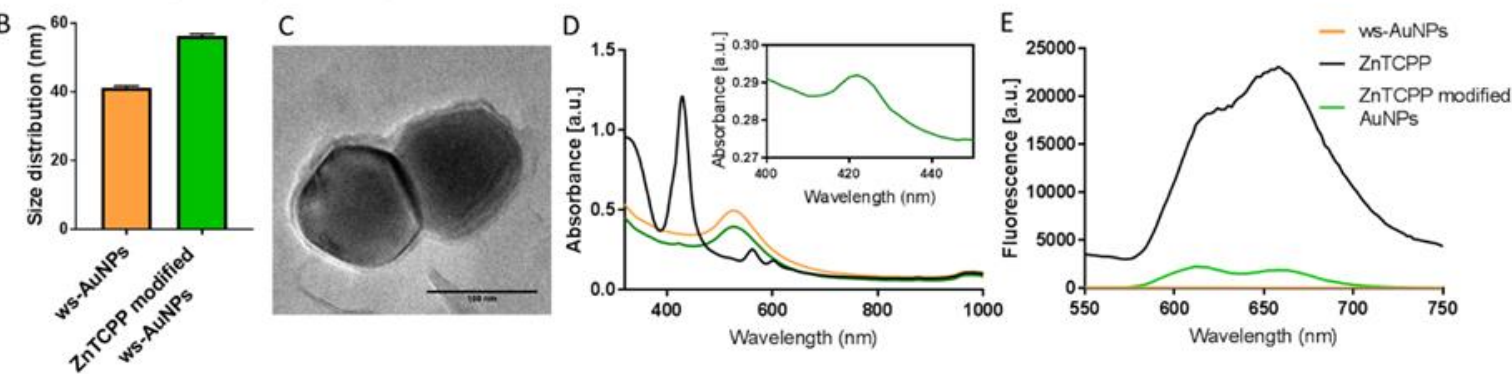

Figure 3. (A) Diagrammatic representations of functionalisation strategy for producing a gemini pyridinium based amphipile incorporating Zn(II)meso-tetrakis(4-carboxyphenyl)porphyrin sodium salt (Na-ZnTCPP) onto water-soluble gold nanoparticles (ws-AuNPs). (B) DLS results showing size distribution of ws-AuNPs before and after chemical modification with Na-ZnTCPP (n=3; SD). (C) TEM image of a pair of Na-ZnTCPP modified ws-AuNPs. Scale bar $100 \mathrm{~nm}$. (D) UV-VIS absorbance spectrum and (E) emission spectrum of free Na-ZnTCPP (black), ws-AuNPs (orange) and Na-ZnTCPP modified ws-AuNPs (green).

Before performing experiments on wireless intracellular communication, cell uptake was studied. In order to test this we incubated the Na-ZnTCPP modified ws-AuNPs with a model Chinese Hamster Ovary (CHO) cell line (Figure 4A). Additionally, we also wanted to determine the time required for the cells to uptake the nanoparticles to maximise the concentration inside the cells, and therefore increase the signal to noise ratio of the electronic reporter in the next 
experiments. Na-ZnTCPP modified ws-AuNPs were incubated with $\mathrm{CHO}$ cells at time intervals up to 4 hours and inductively coupled plasma mass spectrometry (ICP-MS) analysis was performed to detect ws-AuNPs. This was performed on samples containing supernatant and samples containing the cell pellet in order to quantify the amount of gold present outside and inside the cells. Incubation with an initial concentration of $100 \mu \mathrm{g} \mathrm{L}^{-1}$ of Na-ZnTCPP modified wsAuNPs in Hank's Balanced Salt solution (HBSS) was studied for 4 hours. During this period of time, the percentage of viable cells was monitored by Trypan blue analysis. The results obtained for ICP-MS analysis can be seen in Figure 4. On incubations with the cells the concentration of gold in the supernatant was reduced by $27.6 \mu \mathrm{g} \mathrm{L} \mathrm{L}^{-1}$ over the 4 hours, whilst the concentration of the gold associated with the cell pellet rose to approximately $26.4 \mu \mathrm{g} \mathrm{L}^{-1}$. . This provides evidence that the cells were up-taking the Na-ZnTCPP modified ws-AuNPs. Moreover, we quantified the number of Na-ZnTCPP modified ws-AuNPs per cell from the ICP-MS data and found at 30 minutes there were 4 , at 1 hours there were 76 and by 4 hours there were approximately 160 nanoparticles per cell (Figure 4C). Details of this calculation are given in the methods section. For future experiments it appeared that an incubation of 4 hours was suitable for obtaining a high number of Na-ZnTCPP modified ws-AuNPs per cell, thereby maximising our signal to noise ratio. It was also important to show that over the 4 hours the cells were viable and there was no detrimental loss in membrane integrity, which could have affected the results of the ICP-MS due to gold nanoparticles leaking from the cells in to the supernatant. Consequently, we performed a dye membrane exclusions study in which we incubated Trypan blue with cell exposed to the NaZnTCPP modified ws-AuNPs nanoparticles for up to 4 hour (Figure 4B). No difference in membrane viability, and therefore cell death, was observed over the 4 hours suggesting the nanoparticles caused no membrane degradation. 

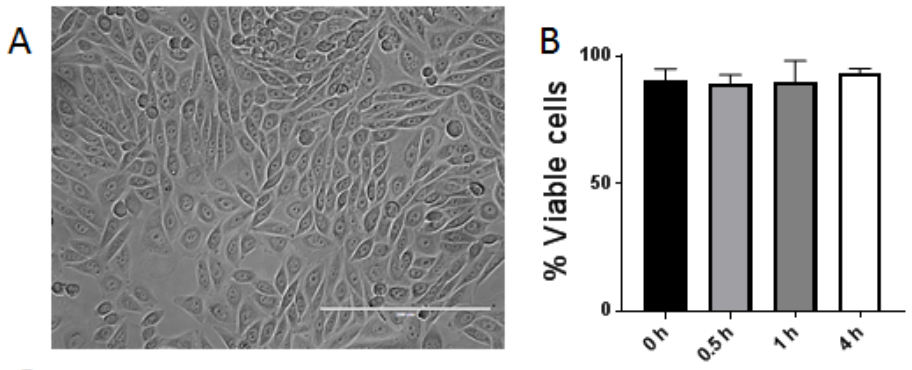

C
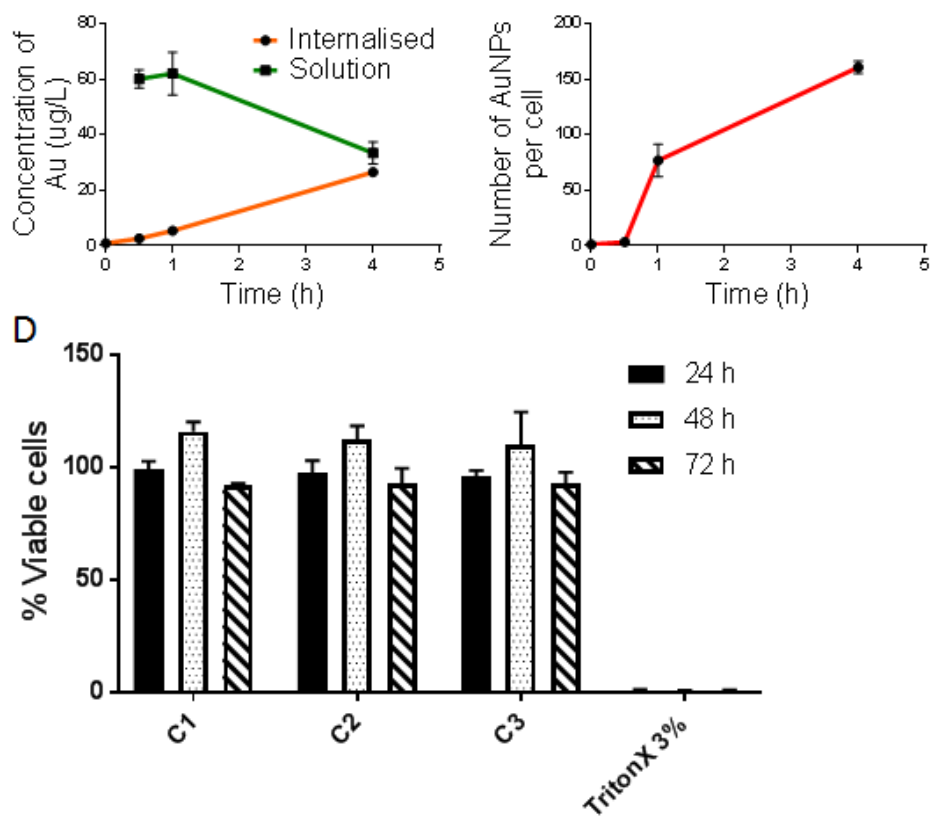

Figure 4 (A) Optical microscopy image of Chinese Hamster Ovary (CHO) cells (scale bar 200 $\mu \mathrm{m})$. (B) Percentage of viable cells calculated using a trypan blue assay. (C) Inductively coupled plasma mass spectrometry (ICP-MS) analysis of concentration of gold internalised in the cells and in supernatant solution (left) and calculation of gold nanoparticles per cell (right). (D) WST-8 metabolic activity assay of $\mathrm{CHO}$ cells incubated with $11.8 \mu \mathrm{M}(\mathrm{C} 1), 2.36 \mu \mathrm{M}(\mathrm{C} 2)$ and $1.18 \mu \mathrm{M}$ (C3) gold nanoparticles for longer periods of time. TritonX-100 was used as positive control. ( $\mathrm{n}=3$ ; SD). 
The trypan blue exclusion study determined that over 4 hours the nanoparticles caused no cell death; however, the practicality of using such a system long term meant that from this data we could not infer if they were biocompatible on longer time scales. Additionally, the trypan blue cell viability assay does not report on sub-lethal toxic effects. As a result, it was important to assess the effect that the modified gold nanoparticles had on the cells for longer periods and to use an assay that could report sub-lethal effects such as a metabolic reporter assay. Subsequently the wellknown WST-8 metabolic reporter assay ${ }^{36}$ was chosen (Figure 4B). Error! No bookmark name given.If cellular metabolism was being perturbed by the nanoparticles, we would expect a drop in the percentage of viable cells as indicated by the positive control, TritonX-100, which is a widely used toxicant and completely stops metabolism. At all the doses investigated, there was no decrease in the absorbance relative to the negative control (culture media only and cells). This indicated that the Na-ZnTCPP modified ws-AuNPs were not inducing detrimental metabolic effects on a longer time scale.

We then proceeded to test our hypothesis that we could electronically communicate with the inside of the cells. It was expected that the redox state of the Na-ZnTCPP could be modulated via external application of potentials, hence shifting the energy levels of the molecule and ultimately reducing the magnitude of the fluorescence. This relationship between the redox state of $\mathrm{Zn}$ porphyrins and their emission fluorescence has been previously studied, and due to the electrochemical reversibility of $\mathrm{Zn}$ porphyrins, it should be possible to switch the fluorescence on and off by controlling the excited-state electron transfer ${ }^{37,38}$. 
The Na-ZnTCPP modified ws-AuNPs (Figure 5A) were incubated with CHO cells for 4 hours to ensure optimal uptake which made them inherently fluorescent, and a sample of cell suspension was placed on the printed electrochemical cell. Due to the electrical properties of cell membranes, acting as resistors and capacitors ${ }^{39}$, higher potentials were applied. A potential difference of 150 V was applied between the feeder electrodes while we simultaneously monitored and collected the fluorescence exposed to a $550 \mathrm{~nm}$ laser excitation source. After the application of the potential difference, we could observe a reduction in the fluorescence inside the cells (Figure 5B, Movie S1). This was confirmed by quantitative measurement of fluorescence intensity of the cells before and after application of potential. Corrected total cell fluorescence in the area of the cells, calculated by applying the formula below ${ }^{40}$, determined a significant $(\mathrm{P}<0.05)$ reduction in the fluorescence (Figure 5C). This occurs as the $\mathrm{Zn}$ is oxidised, causing a reduction in the fluorescence that was not observed in the controls when incubating the CHO cells with ws-AuNPs, as they do not have the porphyrin (Figure S3). In this case there was no fluorescence at all. It is also worth noting that on the application of the potential the background noise increases, which is an artefact of the electrochemistry and therefore results in a lower signal noise. Nevertheless a significant difference was still observable and therefore the results are still valid.

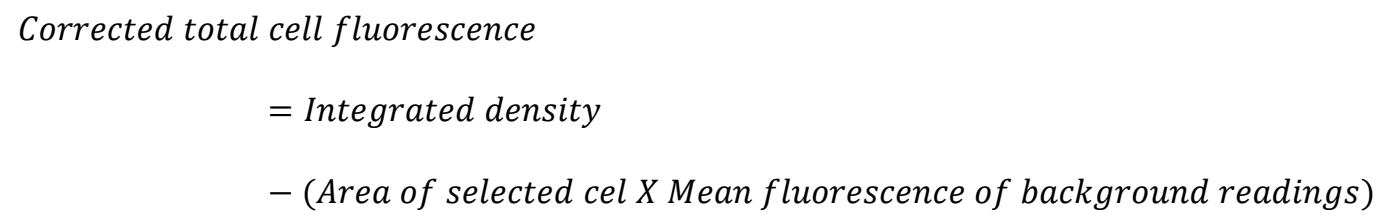

This result indicates that changes in fluorescence are mediated by wireless induced intracellular cell redox changes, as they only occur after the application of external potentials. It is important 
to note that integrity of the cell membrane seems to be intact, as cells conserve their round shape after potential application (Figure 5B). Thus, this represents a new wireless electronic system then can intracellularly communicate with the internal environment of the cells.
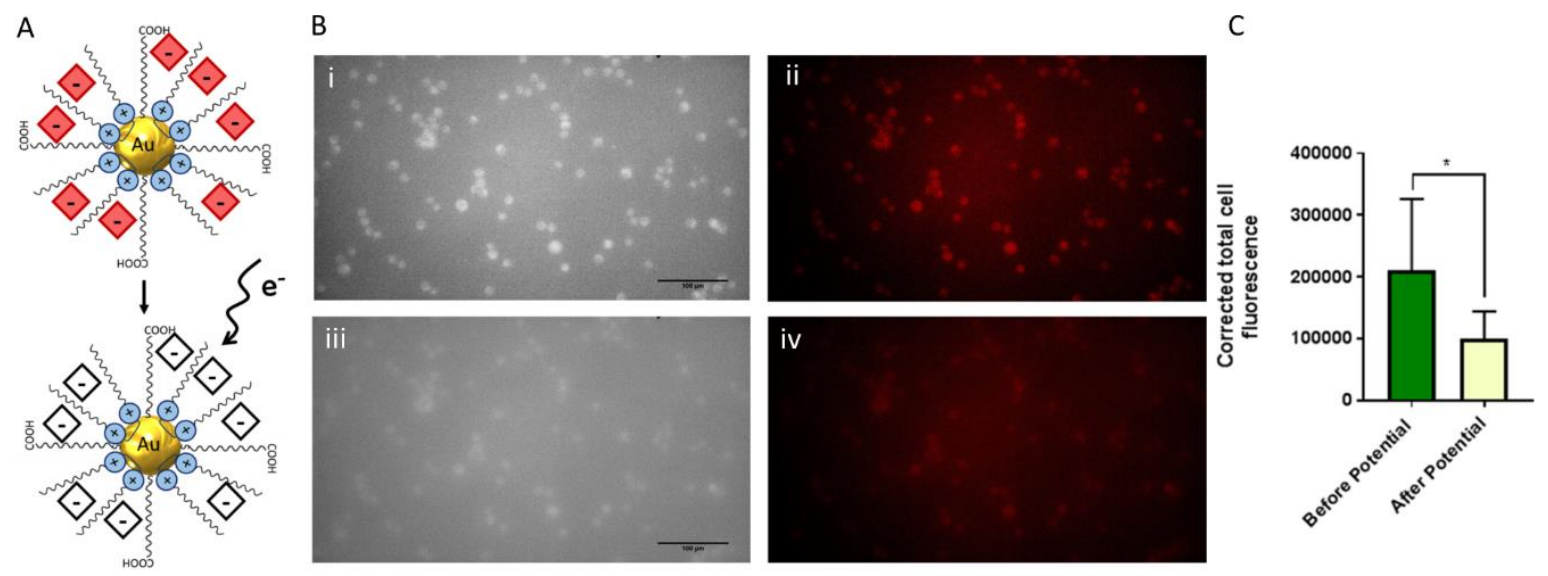

Figure 5. A) Diagram showing the result of the application of potentials. B) Fluorescence microscope images of $\mathrm{CHO}$ cells containing Na-ZnTCPP modified ws-AuNPs (i) before application of potentials and (ii) its correspondent coloured image and (iii) after applying the potential and (iv) coloured image. Scale bar $100 \mu \mathrm{m} \mathrm{C)} \mathrm{Corrected} \mathrm{total} \mathrm{cell} \mathrm{fluorescence} \mathrm{quantified}$ in the area of the cells before and after applying the potential. Statistical significance was calculated using an unpaired two-tailed test $\left(\mathrm{n}=10 ; \mathrm{SD} ;{ }^{*} \mathrm{p}=0.0117\right)$. Scale bar is $100 \mu \mathrm{m}$.

In summary, we have shown that gold nanoparticle surface chemistry could be wirelessly modified by electrical input at relatively low applied electrical potentials inside cells. The gold 
nanoparticles were designed to be water soluble with a gemini pyridinium based amphiphile incorporating $\mathrm{Zn}(\mathrm{II})$ meso-tetrakis(4-carboxylatephenyl)porphyrin sodium salt (Na-ZnTCPP) onto water-soluble gold nanoparticles (ws-AuNPs). These were shown to be biocompatible and could penetrate the membrane of cells. Once the nanoparticles were incubated inside of the cells, an external electrical stimulus was applied and the nanosensors that could convert the electrical input into chemical, via Zn-porphyrin redox modulations, to a fluorescence output. This demonstrates the establishment of a generic wireless method to communicate electronically with the inside of cells. This will have important implications for future non-invasive sensing and actuating platform that may be used to advance the field of bioelectronics and biosensing.

Materials and methods

Materials

Unless otherwise stated, materials were purchased from Sigma-Aldrich, UK

Inkjet printing of an electrochemical cell

An electrochemical cell consisting of two gold feeder electrodes and one silver/silver chloride pseudo reference electrode was inkjet printed. Kapton tape (RS Components, UK) composed of polyimide was attached to 76 x 26 glass slides (Cole-Palmer) and used as substrates. Glass slides were washed with acetone prior to use. Inks consisted of a silver nanoparticle ink (AgNPink) with an approximate $30 \%$ of solid content purchased from ANP Ltd, and a gold nanoparticle ink (AuNPink) containing 12\% of solid content (Printed Electronics Ltd., Tamworth, UK). 
Inks were filtrated (HPLC Nylon $5.0 \mu \mathrm{m}$ syringe filters, Cole-Parmer) and injected into the propylene print cartridge (DMC-11610, $10 \mathrm{pl}$ and DMCLCP-11610), which were fixed to the printhead prior to printing, on a piezo electric drop-on-demand Dimatix Materials Printer (Model DMP-2800, FUJIFILM Dimatix, Inc. Santa Clara, CA). Printheads had 16 jetting nozzles $(21 \mu \mathrm{m}$ in diameter). Bit-maps of patterns were developed by GNU Image Manipulation Program (version 2.8.16) and adapted using the Dimatix materials printer software. Patterns were printed by jetting 846 drops per inch (DPI), corresponding to a drop spacing of $30 \mu \mathrm{m}$, and using custom print waveforms. Single nozzles were used to improve the resolution of the patterns and avoid the formation of clogs. When printing, the temperature was set and held to $100^{\circ} \mathrm{C}$ using a custom-built heater inside the printer. Firing voltages varied over a range of 20-25 V to allow an optimal speed of ink droplet ejection from the nozzles. Sintering of nanoparticles was carried out in an oven at $150^{\circ} \mathrm{C}$ and $250^{\circ} \mathrm{C}$ for an hour for the AgNPink and the AuNPink respectively. Three layers of AgNPink and five layers of AuNPink were printed.

Testing of printed electrochemical cell was carried out at room temperature using a VersaSTAT 4 potentiostat interfaced with a personal computer and integrated with VersaStudio Software (Princeton Applied Research). The supporting electrolyte was phosphate buffer saline (PBS) dissolved in deionised water (0.01 M phosphate buffer, $0.0027 \mathrm{M}$ potassium chloride and $0.137 \mathrm{M}$ sodium chloride), $1 \mathrm{mM}$ potassium hexacyanoferrate (III) in PBS was used as the electroactive species. Potentials are reported vs. an inkjet Ag pseudoreference electrode. Printed gold feeder electrodes were used as working and auxiliary electrodes. Cyclic voltammograms (CVs) were acquired when a potential was applied from $0.8 \mathrm{~V}$ to $-0.3 \mathrm{~V}$ at a scan rate of $5 \mathrm{mV} \mathrm{s}^{-1}$. 
Electrodeposition of palladium onto unmodified gold nanoparticles (u-AuNPs)

$50 \mathrm{~nm}$ unmodified gold nanoparticles, giving an optical density of 1, stabilised in $0.1 \mathrm{mM}$ PBS and reactant free (u-AuNPs) were used as bipolar electrodes within the printed cell, where the gap between gold feeder electrodes was $210 \mu \mathrm{m}$. A solution of $1 \mathrm{mM}$ palladium chloride in PBS was added to the dispersion of u-AuNPs. $20 \mu 1$ of this suspension were placed in contact with all the elements of the system. Chronoamperometry was performed in the aforementioned instrument. 10 $\mathrm{V}$ were applied for varying times of 1,5 and 15 minutes.

Size characterisation of the u-AuNPs dispersion was carried out by Dynamic Light Scattering (DLS) using a Malvern zetasizer Nano ZS (Malvern Instruments, UK) after the electrodeposition. Scanning Electron Microscopy (SEM) was used to examine the morphology of the deposits. The sample preparation required the deposition of the suspensions into a holey carbon Transmission Electron Microscopy (TEM) grid. Visualisation of the nanoparticles was carried out in FEI Quanta 650 SEM. Elemental mapping results were performed with an energy-dispersive X-ray spectrometer (EDX) incorporated in the SEM.

In order to discard $\mathrm{pH}$-induced aggregation, solutions were incubated in $\mathrm{PBS}\left(\mathrm{pH} 7.4\right.$ at $\left.25^{\circ} \mathrm{C}\right)$, a commercial buffer solution at $\mathrm{pH} 4 \pm 0.01$ at $20^{\circ} \mathrm{C}$ (SLS Select) and a commercial buffer solution at $\mathrm{pH} 2 \pm 0.02$ at $25^{\circ} \mathrm{C}$ (Reagecon). Size of particles was measured by DLS in aqueous after 1 and 15 minutes. $\mathrm{pH}$ of the system was also monitored for 15 minutes when the potentials were applied and measured on a $\mathrm{pH}$ meter (Metler Toledo).

Plasmonic-based detection of electrical charge modulation at u-AuNPs 
A darkfield microscopy setup was used to image the voltage effect on the u-AuNPs. In this setup, the sample was illuminated with a $633 \mathrm{~nm}$ collimated light. The sample plane was imaged on CMOS camera (SV643M, Epix) to collect the forward-scattered light by nanoparticles. To study the low voltage effect on u-AuNPs, an electrostatic layer-by-layer self-assembly process was used to bond the particles to a conducting substrate to avoid being washed out while serving as a working electrode. Firstly, a layer of potassium hydroxide $(\mathrm{KOH})$ solution was deposited for 1 hour on a glass cover-slip coated with $10 \mathrm{~nm}$ of Indium-Tin-Oxide (ITO). Then, two synthetic polymers, poly(allylamine hydrochloride) (PAH) and poly(sodium 4-styrenesulfonate) (PSS), were deposited for 30 minutes each. Between all these steps, the substrate was washed with deionised water and dried with nitrogen. Once the polymer layers were completed, a solution of u-AuNPs (125 nm diameter) was drop-coated and dried overnight. For sensitive detection of the voltage effect, the wavelength and the particle size and shape have to be carefully selected. Here, the wavelength of $633 \mathrm{~nm}$ is located at the highest gradient of the scattering spectrum of the 125 $\mathrm{nm}$ u-AuNPs, in aqueous solution, where maximum change in scattering due to the applied voltage is obtained. A sinusoidal voltage modulation with $0.8 \mathrm{Vpp}$ at $4 \mathrm{~Hz}$ was applied to the substrateintegrated nanoparticles, against a platinum reference electrode, while recording modulation of light scattering simultaneously using CMOS camera (SV643M, Epix, Buffalo Grove, IL, USA) with $100 \mathrm{~Hz}$ sampling frequency. To map the voltage effect on the Au nanoparticles, a fast Fourier transform (FFT) of the dynamic scattering intensity was computed for each pixel. The map was produced by selecting the amplitude of the voltage-modulated intensity at the frequency of the applied signal.

Synthesis and characterisation of water soluble gold nanoparticles (ws-AuNPs) 
Details about synthesis and characterisation were described elsewhere ${ }^{32}$. Measurements of absorbance and emission spectra were performed on a Tecan microplate reader. Absorbance was scanned form $200 \mathrm{~nm}$ to $1000 \mathrm{~nm}$ at room temperature with a wavelength step size of $2 \mathrm{~nm}$ of solutions of $1.17 \mathrm{mM}$ of a $\mathrm{Zn}(\mathrm{II})$ meso-tetrakis(4-carboxylatephenyl)porphyrin sodium salt (NaZnTCPP), and $2.77 \mu \mathrm{M}$ ws-AuNPs with and without Na-ZnTCPP in PBS. Emission spectra of the previous solutions was measured from $550 \mathrm{~nm}$ to $750 \mathrm{~nm}$ at an excitation wavelength of $420 \mathrm{~nm}$ at room temperature. A $10 \mu \mathrm{l}$ drop of suspension of Na-ZnTCPP modified ws-AuNPs was deposited on a TEM carbon-coated copper grid (Agar Scientific) and dried at room temperature before measurements. TEM measurements were performed on a Jeol 2100 Plus TEM at an accelerating voltage of $80 \mathrm{kV}$.

\section{Cell culture}

Chinese Hamster Ovary (CHO) cells were cultured in corning T-75 $\mathrm{cm}^{2}$ flasks in $15 \mathrm{ml}$ of media supplemented with $10 \%$ foetal bovine serum (FBS), 2.4\% HEPES buffer solution and 1\% penicillin/streptomycin for 2-3 days in an incubator at $37^{\circ} \mathrm{C}$ in $5 \% \mathrm{CO}_{2}$ atmosphere and passaged with trypsin when $70-80 \%$ confluent.

Uptake of Na-ZnTCPP modified ws-AuNPs was analysed by inductively coupled plasma mass spectrometry (ICP-MS). Approximately $1.50 \times 10^{-3}$ cells were reseeded on 6 well-plates 24 hours before experiments. Na-ZnTCPP modified ws-AuNPs were added at a final concentration of 2.54 $\mu \mathrm{M}$ in Hank's Balanced Salt solution (HBSS) and incubated for $0.5,1$ and 4 hours. After each time point, solution was collected, centrifuged at $4000 \mathrm{rpm}$ for 5 minutes and pellet saved for ICP-MS analysis. Cells were rinsed three times with PBS and trypsinised and collected in a Falcon tube. 
$10 \mu 1$ of cell suspension were mixed with trypan blue in a ration 1:1 and counted on a haemocytometer after each time point. Well plates were washed with 10\% FBS in HBSS solution and collected with the cells prior centrifugation at $1200 \mathrm{rpm}$ for 5 minutes. Pellets containing the cells were saved for ICP-MS analysis. Solutions were digested in 5\% aqua regia (trace metal grade $\mathrm{HCl}$ and $\mathrm{HNO}_{3}$ in a proportion of 3:1) and left overnight. After digestion, solutions were diluted to reach a final concentration of acid of $2 \%$, filtered and collected for analysis on an iCAPQ Thermo Fischer inductively coupled plasma mass spectrometer. Standard solutions were used to develop a calibration curve. The number of nanoparticles per cell was calculated by firstly gaging the number of $\mathrm{Au}$ atoms present in the $50 \mathrm{~nm}$ nanoparticles assuming a crystalline structure. This allows us to know the mass of Au per nanoparticle and compare it to ICP-MS results to obtain the total number of particles in each sample. The cells were counted as described earlier, we can then calculate the number of particles per cell at the different time points.

Biocompatibility studies for longer incubation times were performed using a water-soluble tetrazolium salt (WST-8) assay. 7500 cells were incubated on 96 well plates 24 hours prior experiment. Na-ZnTCPP modified ws-AuNPs at different concentrations were added (C1: 11.8 $\mu \mathrm{M}, \mathrm{C} 2: 2.36 \mu \mathrm{M}$ and $\mathrm{C} 3: 1.18 \mu \mathrm{M})$ and incubated with cells for 24,48 and 72 hours. After each incubation time, media was replaced with $10 \%$ WST- 8 in complete DMEM and incubated for an hour before reading absorbance at $450 \mathrm{~nm}$ in a Tecan microplate reader. Controls (culture media as negative control and TritonX-100 3\% as positive control) and blanks were used. Values are presented relative to negative controls.

Intracellular wireless actuation 
CHO cells were incubated in a 6 well plate with $2.54 \mu \mathrm{M}$ of Na-ZnTCPP modified ws-AuNPs, incubated for 4 hours and suspended. $20 \mu \mathrm{l}$ of suspension containing cells was placed between gold feeder electrodes and $150 \mathrm{~V}$ were applied using an in-house-made voltage power supply. 550 $\mathrm{nm}$ laser was used as excitation source. Changes in fluorescence of modified particles were monitored using a Nikon ECLIPSE TE300 fluorescent microscope equipped with a QImaging optiMOS, Scientific CMOS camera. ImageJ 1.52a open source software was used to perform image analysis and quantification of the corrected total cell fluorescence. Statistical significance was calculated using an unpaired t-test on Graphpad Prism 7.01.

\section{Associated content}

The following files are available free of charge.

Supporting figures can be found in NanoLetters-Sup-001-S1.PDF (.PDF file)

Fluorescence microscopy video of Na-ZnTCPP modified ws-AuNPs during the application of a potential difference of $150 \mathrm{~V}$. NanoLetters-Sup-002-MovieS1.WMA (.WMA file)

\section{AUTHOR INFORMATION}

\section{Corresponding Author}

*E-mail: Frankie.Rawson@nottingham.ac.uk Tel.: (+44) 011584698 


\section{Author Contributions}

PSA performed printing of electrodes, electrochemical experiments, characterization and cell work. SAA concept, instrumentation design and signal processing of plasmonic imaging, SAA and RFD performed the plasmonic measurements. MAR and LPG performed the synthesis and characterization of ws-AuNPs and Na-ZnTCPP. PSA, SAA and FJR wrote the manuscript. All the authors read, commented and approved the final manuscript.

\section{Funding Sources}

This work was supported by the Engineering and Physical Sciences Research Council EP/R004072/1, EP/K005138/1, EP/R004072/1, E0P/M50810X/1 and EU ERDF (FEDER) funds and MINECO through the Spanish Government (TEC2017-85059-C3-2-R). The University of Nottingham for funding the Nottingham Research Fellowship currently held by Dr Rawson.

\section{ACKNOWLEDGMENT}

Prof Alexander Kuhn is thanked for insightful discussion. Dr. Scott Young and Dr. Saul VazquezReina are thanked for their assistance with ICP-MS analysis. Dr. Marion Limo is thanked for help provided for TEM analysis and and Dr. Michael Fey for assistance on SEM analysis. The authors thank the Nanoscale and Microscale Research Centre (nmRC) for providing access to instrumentation.

\section{ABBREVIATIONS}


Chinese Hamster Ovary cells, CHO cells; Dynamic light scattering, DLS; Energy dispersive Xray, EDX; Fast Fourier transform, FFT; Hank's balanced salt solution, HBSS; Indium-tin-oxide, ITO; Inductively coupled plasma mass spectrometry, ICP-MS; Scanning electron microscopy, SEM; Sodium Zn(II)meso-tetrakis(4-carboxylatephenyl)porphyrin, Na-ZnTCPP: Unmodified gold nanoparticles, u-AuNPs; Water-soluble gold nanoparticles, ws-AuNPs; Water-soluble tetrazolium salt, WST-8.

1. Famm, K.; Litt, B.; Tracey, K. J.; Boyden, E. S.; Slaoui, M. Nature 2013, 496, (7444), $159-61$.

2. Birmingham, K.; Gradinaru, V.; Anikeeva, P.; Grill, W. M.; Pikov, V.; McLaughlin, B.; Pasricha, P.; Weber, D.; Ludwig, K.; Famm, K. Nat Rev Drug Discov 2014, 13, (6), 399-400.

3. $\quad$ Sanjuan-Alberte, P.; Alexander, M. R.; Hague, R. J. M.; Rawson, F. J. Bioelectron Med 2018, 4, (1), 1 .

4. Rawson, F. J.; Cole, M. T.; Hicks, J. M.; Aylott, J. W.; Milne, W. I.; Collins, C. M.; Jackson, S. K.; Silman, N. J.; Mendes, P. M. Sci Rep 2016, 6, 37672.

5. $\quad$ Rawson, F. J.; Hicks, J.; Dodd, N.; Abate, W.; Garrett, D. J.; Yip, N.; Fejer, G.; Downard, A. J.; Baronian, K. H. R.; Jackson, S. K. ACS Appl. Mater. Interf. 2015, 7, (42), 23527-23537.

6. Rawson, F. J.; Yeung, C. L.; Jackson, S. K.; Mendes, P. M. Nano letters 2012, 13, (1), 18.

7. Qing, Q.; Jiang, Z.; Xu, L.; Gao, R.; Mai, L.; Lieber, C. M. Nat Nanotechnol 2014, 9, (2), $142-7$. 
8. Zhang, A.; Lieber, C. M. Chem Rev 2016, 116, (1), 215-57.

9. Actis, P.; Tokar, S.; Clausmeyer, J.; Babakinejad, B.; Mikhaleva, S.; Cornut, R.;

Takahashi, Y.; Lopez Cordoba, A.; Novak, P.; Shevchuck, A. I.; Dougan, J. A.; Kazarian, S. G.;

Gorelkin, P. V.; Erofeev, A. S.; Yaminsky, I. V.; Unwin, P. R.; Schuhmann, W.; Klenerman, D.;

Rusakov, D. A.; Sviderskaya, E. V.; Korchev, Y. E. ACS Nano 2014, 8, (1), 875-84.

10. Wang, Y.; Noel, J. M.; Velmurugan, J.; Nogala, W.; Mirkin, M. V.; Lu, C.; Guille

Collignon, M.; Lemaitre, F.; Amatore, C. Proc Natl Acad Sci U S A 2012, 109, (29), 11534-9.

11. Liu, J.; Wen, J.; Zhang, Z. R.; Liu, H. J.; Sun, Y. Microsyst Nanoeng 2015, 1, 15020.

12. Lee, D.; Lee, D.; Won, Y.; Hong, H.; Kim, Y.; Song, H.; Pyun, J. C.; Cho, Y. S.; Ryu, W.; Moon, J. Small 2016, 12, (11), 1446-1457.

13. Loget, G.; Kuhn, A. Anal Bioanal Chem 2011, 400, (6), 1691-704.

14. Fosdick, S. E.; Knust, K. N.; Scida, K.; Crooks, R. M. Angew Chem Int Ed 2013, 52, (40), 10438-10456.

15. Loget, G.; Roche, J.; Kuhn, A. Adv Mater 2012, 24, (37), 5111-6, 5144.

16. Warakulwit, C.; Nguyen, T.; Majimel, J.; Delville, M. H.; Lapeyre, V.; Garrigue, P.; Ravaine, V.; Limtrakul, J.; Kuhn, A. Nano Lett 2008, 8, (2), 500-4.

17. Casal-Dujat, L.; Rodrigues, M.; Yague, A.; Calpena, A. C.; Amabilino, D. B.; GonzalezLinares, J.; Borras, M.; Perez-Garcia, L. Langmuir 2012, 28, (5), 2368-81.

18. Connor, E. E.; Mwamuka, J.; Gole, A.; Murphy, C. J.; Wyatt, M. D. Small 2005, 1, (3), 325-327. 
19. Penon, O.; Patino, T.; Barrios, L.; Nogues, C.; Amabilino, D. B.; Wurst, K.; PerezGarcia, L. ChemistryOpen 2015, 4, (2), 127-36.

20. Alkilany, A. M.; Thompson, L. B.; Boulos, S. P.; Sisco, P. N.; Murphy, C. J. Adv Drug Deliver Rev 2012, 64, (2), 190-199.

21. Dreaden, E. C.; Alkilany, A. M.; Huang, X.; Murphy, C. J.; El-Sayed, M. A. Chem Soc Rev 2012, 41, (7), 2740-79.

22. Giljohann, D. A.; Seferos, D. S.; Daniel, W. L.; Massich, M. D.; Patel, P. C.; Mirkin, C. A. Angew Chem Int Ed Engl 2010, 49, (19), 3280-94.

23. Di Martino, G.; Turek, V. A.; Lombardi, A.; Szabó, I.; de Nijs, B.; Kuhn, A.; Rosta, E.; Baumberg, J. J. Nano Lett. 2017, 17, (8), 4840-4845.

24. Rasmussen, M.; Serov, A.; Artyushkova, K.; Chen, D.; Rose, T. C.; Atanassov, P.; Harris, J.; Minteer, S. Chem ElectroChem 2018.

25. Perrin, D. D.; Dempsey, B.; Serjeant, E. P., pKa prediction for organic acids and bases. Chapman and Hall: London; New York, 1981; Vol. 1.

26. Jing, C.; Rawson, F. J.; Zhou, H.; Shi, X.; Li, W. H.; Li, D. W.; Long, Y. T. Anal Chem 2014, 86, (11), 5513-5518.

27. Zhou, H.; Liu, Q.; Rawson, F. J.; Ma, W.; Li, D. W.; Li, D.; Long, Y. T. Chem Comm 2015, 51, (15), 3223-3226.

28. Abayzeed, S. A.; Smith, R. J.; Webb, K. F.; Somekh, M. G.; See, C. W. Optics Express 2017, 25, (25), 31552-31567.

29. Huang, Y.; Pitter, M. C.; Somekh, M. G. Langmuir 2011, 27, (22), 13950-61. 
30. Hasheminejad, M.; Fang, Y.; Li, M.; Jiang, Y.; Wang, W.; Chen, H. Y. Angew Chem Int Ed Engl 2017, 56, (6), 1629-1633.

31. Huang, Y.; Pitter, M. C.; Somekh, M. G. ACS Appl Mater Interfaces 2012, 4, (8), 382936.

32. Alea-Reyes, M. E.; Soriano, J.; Mora-Espi, I.; Rodrigues, M.; Russell, D. A.; Barrios, L.; Perez-Garcia, L. Colloids Surf B Biointerfaces 2017, 158, 602-609.

33. Xiao, X. W.; Xu, W.; Zhang, D. Q.; Xu, H.; Lu, H. Y.; Zhu, D. B. J Mater Chem 2005, $15,(26), 2557-2561$.

34. Lahav, M.; Gabriel, T.; Shipway, A. N.; Willner, I. J Am Chem Soc 1999, 121, (1), 258259.

35. Apanasovich, V.; Novikov, E.; Yatskov, N.; Koehorst, R.; Schaafsma, T.; Van Hoek, A. J. Appl. Spectrosc. 1999, 66, (4), 613-616.

36. Tominaga, H.; Ishiyama, M.; Ohseto, F.; Sasamoto, K.; Hamamoto, T.; Suzuki, K.; Watanabe, M. Anal Commun 1999, 36, (2), 47-50.

37. Rochford, J.; Rooney, A. D.; Pryce, M. T. Inorg Chem 2007, 46, (18), 7247-9.

38. Norel, L.; Tourbillon, C.; Warnan, J.; Audibert, J. F.; Pellegrin, Y.; Miomandre, F.; Odobel, F.; Rigaut, S. Dalton Trans 2018, 47, (25), 8364-8374.

39. Goldman, D. E. J Gen Physiol 1943, 27, (1), 37-60.

40. Gavet, O.; Pines, J. Dev Cell 2010, 18, (4), 533-43. 


\title{
Wireless bioelectronic nanosystems for intracellular communication
}

\author{
Paola Sanjuán-Alberte ${ }^{a, b}$, Sidahmed A Abayzeed ${ }^{c}$, Rafael Fuentes-Domínguez ${ }^{c}$, María E \\ Alea-Reyes ${ }^{d}$, Matthew Clarkc, Richard JM Hague ${ }^{b}$,Morgan R Alexandere, Lluïsa Pérez-Garcíae, \\ Frankie J Rawson ${ }^{a *}$ \\ a Regenerative Medicine and Cellular Therapies, School of Pharmacy, University of Nottingham, \\ Nottingham, NG7 2RD UK \\ ${ }^{b}$ Centre for Additive Manufacturing, Faculty of Engineering, University of Nottingham, Nottingham, \\ NG7 2RD, UK
}

c Optics and Photonics Research Group, Faculty of Engineering, University of Nottingham, Nottingham, NG7 2RD, UK

d Departament de Farmacologia, Toxicologia i Química Terapèutica, Universitat de Barcelona, Avda. Joan XXIII 27-31, 08028 Barcelona, Spain

e Advanced Materials and Healthcare Technologies, School of Pharmacy, University of Nottingham, Nottingham, NG7 2RD, UK 


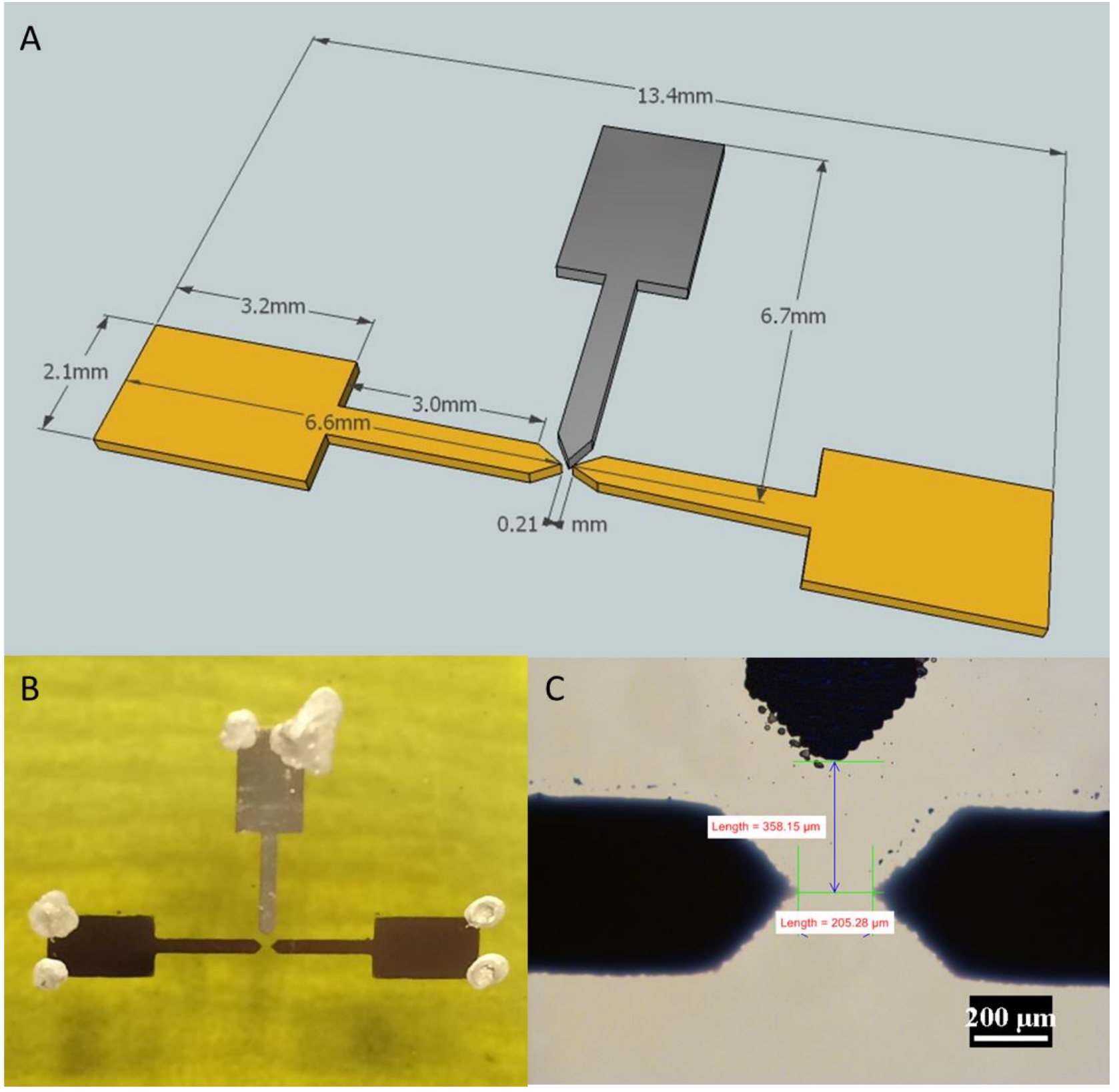

Figure S1. (A) Design and dimensions of an electrochemical cell consisting in two gold feeder electrodes and one silver pseudo-reference electrode. (B) Image of the inkjet printed system and (C) optical microscopy image of the gap between feeder electrodes. 


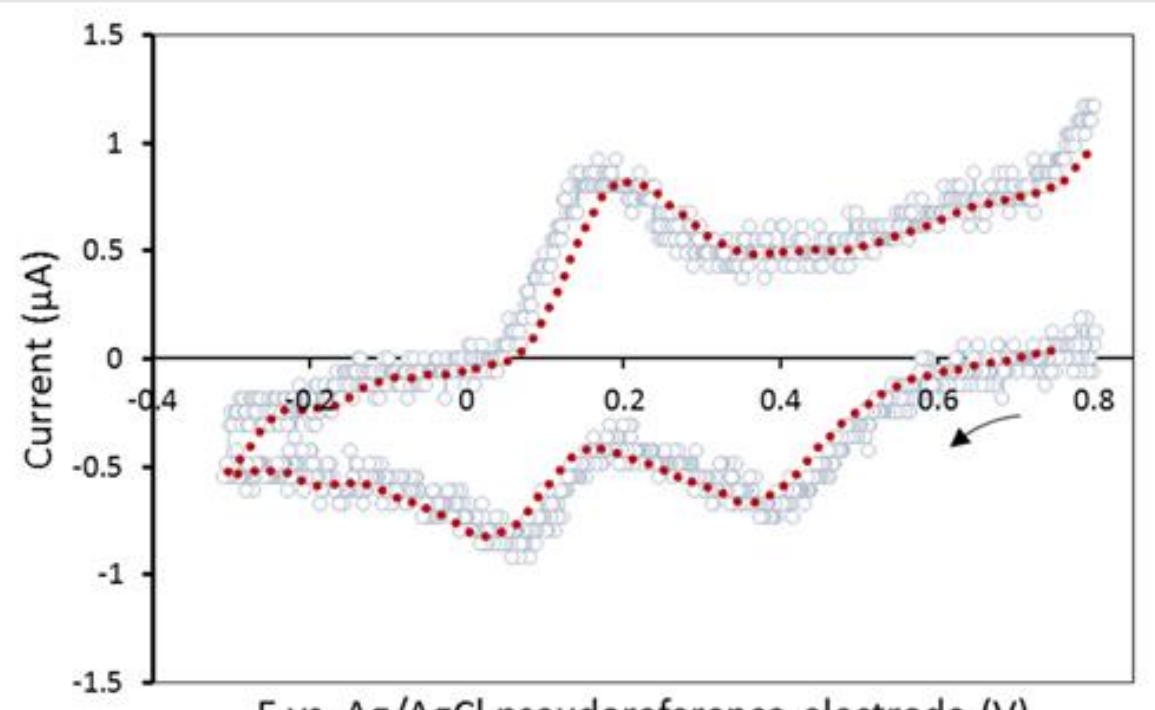

$\mathrm{E}$ vs. $\mathrm{Ag} / \mathrm{AgCl}$ pseudoreference electrode (V)

Figure S2. Cyclic voltammogram obtained using an inkjet printed electrochemical cell at a scan rate of $5 \mathrm{mV} \mathrm{s}^{-1}$ for $1 \mathrm{mM}$ potassium hexacyanoferrate (III) in phosphate buffer saline solution. Blue dots represent the points measured and red line the average values.

The functionality of the electrochemical cell was established by elucidating the redox behaviour of one of the most widely used and redox active molecule, potassium hexacyanoferrate (III). Cyclic voltammetry was performed on a solution of $1 \mathrm{mM}$ potassium hexacyanoferrate (III) in phosphate buffer saline (PBS) at a scan rate of $5 \mathrm{mV} \mathrm{s}^{-1}$. Reduction and oxidation peaks were observed at $0.02 \mathrm{~V}$ and $0.19 \mathrm{~V}$, respectively (Figure S2). The characteristic peak of gold reduction was also identified at $0.37 \mathrm{~V}$. 


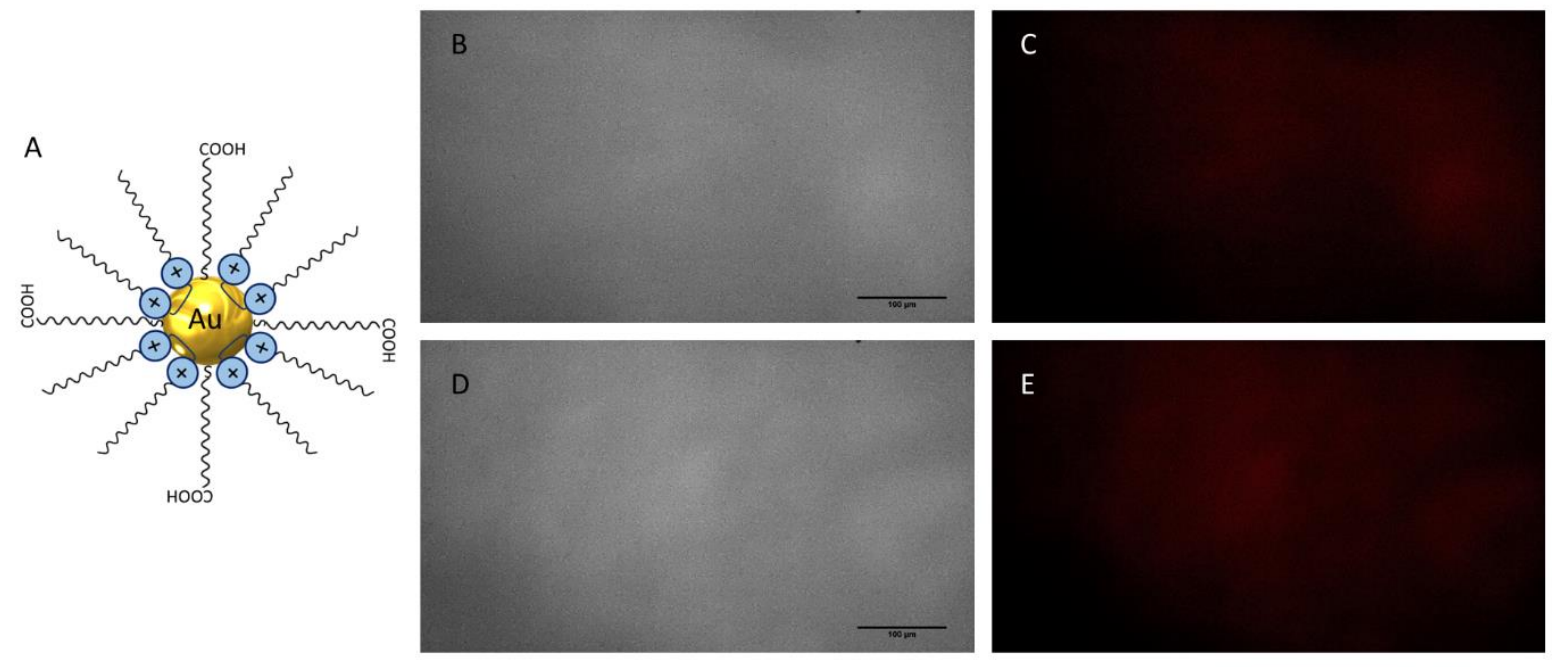

Figure S3. A) Diagram showing the ws-AuNPs incubated with $\mathrm{CHO}$ cells used as negative controls. Fluorescence microscope images of $\mathrm{CHO}$ cells containing ws-AuNPs (B) before application of potentials and (C) coloured image, and (D) after applying the potential and (E) coloured image.

MovieS1. Fluorescence microscopy of CHO cells containing ZnTCPP modified ws-AuNPs during the application of a potential difference 
Wireless bioelectronic nanosystem for intracellular commu... (1.72 MiB) view on ChemRxiv • download file 
Other files

Vid.xspf (557.00 B)

view on ChemRxiv • download file 